\title{
Lysosomal dysfunction and autophagy blockade contribute to autophagy-related cancer suppressing peptide-induced cytotoxic death of cervical cancer cells through the AMPK/mTOR pathway
}

Yang Yang ${ }^{1}$, Qi Wang ${ }^{1}$, Dongjian Song ${ }^{1}$, Ruirui Zen ${ }^{1}$, Lei Zhang ${ }^{1}$, Yingjun Wang ${ }^{2}$, Heying Yang ${ }^{1}$, Da Zhang ${ }^{1}$, Jia Jia', Jiao Zhang ${ }^{1}$ and Jiaxiang Wang ${ }^{1 *}$

\begin{abstract}
Background: Autophagy is an intracellular process through which intracellular components are recycled in response to nutrient or growth factor deficiency to maintain homeostasis. We identified the peptide autophagyrelated cancer-suppressing peptide (ARCSP), a potential antitumor peptide that disrupts intracellular homeostasis by blocking autophagic flux and causes cytotoxic death.

Methods: The proliferative ability of ARCSP-treated cervical cancer cells was examined by the CCK8, EdU, and colony formation assays. The TUNEL assay was used to detect apoptosis. Mitochondrial function was evaluated based on the mitochondrial membrane potential. Autophagic flux was detected by immunofluorescence and confocal microscopy. The autophagy-related proteins AMPK, Raptor, mTOR, p62, LC3B, atg7, Rab7, LAMP1, LAMP2, and cathepsin D were detected by Immunoblotting. The antitumor effect of ARCSP was explored in vivo by establishing a transplant tumor model in nude mice.
\end{abstract}

Results: The results demonstrated that ARCSP induced cell death and inhibited proliferation. ARCSP induced AMPK mTOR activation, resulting in the accumulation of the proteins LC3B, p62 and Atg7. ARCSP also blocked autophagosome-lysosome fusion by inhibiting endosomal maturation and increasing the lysosomal $\mathrm{pH}$. The accumulation of nonfused autophagosomes exacerbated cytotoxic death, whereas knocking down Atg7 reversed the cytotoxic death induced by ARCSP. ARCSP-treated cells exhibited increased cytotoxic death after cotreatment with an autophagy inhibitor (Chloroquine CQ). Furthermore, the tumors of ARCSP-treated nude mice were significantly smaller than those of untreated mice.

Conclusions: Our findings demonstrate that ARCSP, a novel lethal nonfused autophagosome inducer, might cause mitochondrial dysfunction and autophagy-related cytotoxic death and is thus a prospective agent for cancer therapy.

Keywords: Cervical cancer, ARCSP, Autophagic flux, Nonfused autophagosome, Autophagy-related cytotoxic death

\footnotetext{
*Correspondence: wangjx101@126.com

'Department of Pediatric Surgery, The First Affiliated Hospital of Zhengzhou University, Zhengzhou 450052, Henan, China

Full list of author information is available at the end of the article
}

\section{$\triangle B M C$}

(c) The Author(s). 2020 Open Access This article is licensed under a Creative Commons Attribution 4.0 International License, which permits use, sharing, adaptation, distribution and reproduction in any medium or format, as long as you give appropriate credit to the original author(s) and the source, provide a link to the Creative Commons licence, and indicate if changes were made. The images or other third party material in this article are included in the article's Creative Commons licence, unless indicated otherwise in a credit line to the material. If material is not included in the article's Creative Commons licence and your intended use is not permitted by statutory regulation or exceeds the permitted use, you will need to obtain permission directly from the copyright holder. To view a copy of this licence, visit http://creativecommons.org/licenses/by/4.0/ The Creative Commons Public Domain Dedication waiver (http://creativecommons.org/publicdomain/zero/1.0/) applies to the data made available in this article, unless otherwise stated in a credit line to the data. 


\section{Background}

Cervical cancer is the fourth most common malignancy in women worldwide and the third most common cause of cancer death in low-income and middle-income countries [1]. The combination of cisplatin and paclitaxel has been the standard of treatment for advanced cervical cancer for many years, but its efficiency is only 20 to $30 \%$ [2]. Tumor cells have the ability to evade apoptosis, which can cause tumors to become resistant to chemotherapeutic drugs [3]. Therefore, regulation of cell death may be an alternative therapeutic strategy for cervical cancer.

Our previous study identified a peptide (detected at $\mathrm{m} / \mathrm{z} 6455.5 \mathrm{Da}$ by proteomics) that is upregulated in healthy children and downregulated in Wilms tumors [4]. This peptide consists of 55 amino acids and is the smallest member of the apolipoprotein $C$ family. Two forms of apolipoprotein C1 (APOC1) have been found in the plasma, a mature peptide at $\mathrm{m} / \mathrm{z} 6630 \mathrm{Da}(57$ amino acids) [5] and a shear peptide at $\mathrm{m} / \mathrm{z} 6432 \mathrm{Da}$ (55 amino acids) [6]. These two forms of peptides play an important role in the body, participating in different physiological and pathological reactions. The levels of the peptide at $\mathrm{m} / \mathrm{z} 6432 \mathrm{Da}$ are significantly reduced in the serum of non-small cell lung cancer [7], papillary thyroid carcinoma [8], triple negative breast cancer [9], and nephroblastoma $[4,10]$ patients compared to normal controls, indicating that it may be a potential biomarker for tumors. These specific protein markers play an important role in the diagnosis and treatment of malignant tumors [11]. For example, the peptide at $\mathrm{m} / \mathrm{z}$ $6432 \mathrm{Da}$ can inhibit the proliferation of nephroblastoma cells by regulating the $\mathrm{Wnt} / \beta$-catenin pathway and has a potential antitumor effect [4]. Moreover, we found for the first time that the peptide at $\mathrm{m} / \mathrm{z} 6432 \mathrm{Da}$ can inhibit the proliferation of cervical cancer cells by regulating autophagy; thus, we temporarily named the peptide at $\mathrm{m} / \mathrm{z}$ $6432 \mathrm{Da}$ autophagy-related tumor suppressor peptide (ARCSP). In this study, we further explored the relationship between ARCSP-induced cell death and autophagy.

Autophagy is a lysosomal-mediated form of degradation in cells. The process of autophagy includes the formation of autophagosomes, autophagosome-lysosomal fusion, and autophagolysosomal degradation [12]. During degradation, an acidic $\mathrm{pH}$ and the enzymatic action of lysosomal hydrolase leads to destruction of the inner membrane of autophagosomes and the elimination of autophagolysosomes, thereby maintaining cell homeostasis [13]. Abnormalities in the clearance process are associated with a variety of pathologies, including oncogenesis, neurodegenerative diseases, metabolic diseases, and immune-related diseases [14]. It has been found that abnormal accumulation of autophagosomes and impaired autophagolysosomes can induce tumor cell death [15-17]. Sustained and excessive induction of autophagy by anticancer drugs induces irreversible destruction of cellular contents, ultimately leading to cell death [18]. Because ARCSP is a cytotoxic peptide, it, like other peptides, may cause cellular stress [19]. We hypothesized that ARCSP is an antitumor peptide and confirmed our conjecture by testing its antiproliferative effect on cervical cancer, esophageal cancer, neuroblastoma, and kidney cancer cells. It is reasonable to assume that autophagy may be involved in ARCSP-induced cytotoxic death.

In this study, we found that ARCSP induced the accumulation of nonfused autophagosomes by activating the AMPK/mTOR pathway, inhibiting proliferation and causing cytotoxic death of cervical cancer cells. ARCSPinduced cytotoxic death of cells may have mainly resulted from increased ROS levels caused by mitochondrial dysfunction and accumulation of a large number of nonfused autophagosomes. ARCSP had a cytotoxic effect on cervical cancer cells both in vitro and in vivo. These findings indicate that ARCSP is a promising antitumor peptide.

\section{Materials and methods \\ Cell culture}

Human cervical adenocarcinoma cells (HeLa cells), human cervical adenocarcinoma intestinal metastasis cells (CaSki cells), human normal cervical epithelial cells (HCerEpiC cells), and human normal liver epithelial cells (LO-2 cells) were purchased from the Cell Bank of the Shanghai Institute of Chinese Academy of Sciences. These cell lines were maintained in RPMI 1640 with $10 \%$ FBS and incubated in a humidified incubator $(5 \%$ $\mathrm{CO}_{2}$ at $37^{\circ} \mathrm{C}$ ); the medium was changed every 2 days.

\section{Synthesis of ARCSP}

ARCSP was synthesized by solid-phase synthesis of FOMC-protected amino acids and purchased from Life Protein Biotechnology Company (Beijing, China). Its sequence was DVSSALDKLKEFGNTLEDKARELISRIKQS ELSAKMREWFSETFQKVKEKLKIDS (Table 1), and the secondary structure of ARCSP was predicted and modeled by the molecular modeling server (SWISS-MODEL, Switzerland) (Fig. 1a). The purity of ARCSP was more than $95 \%$, as was confirmed by high-performance liquid chromatography (HPLC) analysis (Fig. S1A), and mass spectrometry (MS) was performed to characterize the peptide (Fig. S1B). In addition, a part of ARCSP was labeled with fluorescein isothiocyanate (ARCSP-FITC) for Immunofluorescence. The mother liquor $(2 \mathrm{mg} / \mathrm{mL}$ or $300 \mu \mathrm{M})$ was prepared in RPMI 1640 with $10 \%$ FBS and then diluted to the working concentration with different media. 
Table 1 The amino acid sequence and related information of ARCSP

\begin{tabular}{ll}
\hline Sequence interpretation and physiochemical properties of ARCSP & \\
\hline Single letter code & DVSSALDKLKEFGNTLEDKARELISRIKQSELSAKMREWFSETFQKVKEKLKIDS \\
Triple letter code & Asp -Val -Ser -Ser -Ala -Leu -Asp -Lys -Leu -Lys -Glu -Phe -Gly -Asn -Thr -Leu \\
& - Glu -Asp -Lys -Ala -Arg -Glu -Leu -lle -Ser -Arg -lle -Lys -Gln -Ser -Glu \\
& -Leu -Ser -Ala -Lys -Met -Arg -Glu -Trp -Phe -Ser -Glu -Thr -Phe -Gln -Lys \\
Number of residues & - Val -Lys -Glu -Lys -Leu -Lys -lle -Asp -Ser \\
Molecular weight & 55 \\
Extinction coefficient & $6432.41 \mathrm{~g} / \mathrm{mol}^{-1}$ \\
Iso-electric point & $5690 \mathrm{M}^{-1} \mathrm{~cm}^{-1}$ \\
Net charge at pH 7 & $\mathrm{pH}=9.4$ \\
Estimated solubility & 1 \\
\hline
\end{tabular}

\section{Reagents and antibodies}

The reagents used in this study were purchased from Chinese suppliers: Z-VAD-fmk (CSNpharm, CSN15936, Chicago, USA), CQ (Sigma-Aldrich, C6628, St. Louis, MO, USA), NAC N-acetyl-L-cysteine (Beyotime, S0077, Shanghai, China), AO (Sigma-Aldrich, A6014), 3-MA (Selleck, S2767, Houston, Texas, USA), rapamycin (Selleck, S1039), Cisplatin (Selleck, S1166), and Dorsomorphin (Selleck, S7846). The following antibodies were also purchased from Chinese suppliers: GAPDH (Proteintech, 10,494-1-AP, Wuhan, China), cathepsin D (Proteintech, 21,327-1-AP), PCNA (Proteintech, 10,205-2AP), Ki-67 (Proteintech, 27,309-1-AP), LAMP2 (Proteintech, 66,301-1-lg), p70s6K (Proteintech, 14,485-1AP), tubulin (Proteintech,1124-1-AP), P21(Proteintech, 10,355-1- AP), cleaved-caspase9 (Asp175) (CST, 52873, Beverly, MA, USA), cleaved caspase 8 (Asp391) (CST, 9496), Bax (CST 2774), Bid (CST,2003), Raptor (CST, 2282), p-raptor(Ser792) (CST,2083), Rab7 (CST,9367), AMPK (CST, 5832), p-AMPK (CST, 2535), mTOR (CST, 2983), p-mTOR (CST,5536), p-p70s6K (CST, 9234), LC3B (CST, 3868), LAMP1 (CST 15665), Atg7 (CST,8558), p62 (CST, 88588).

\section{Cell viability assay}

Cells were cultured in 96-well plates with ARCSP for different durations. Then, the cells were washed, $110 \mu \mathrm{L}$ of fresh medium containing CCK8 reagent (Dojindo, CK 04, Tokyo, Japan) was added, and the cells were incubated for $1-2 \mathrm{~h}$. The absorbance was measured at 450 $\mathrm{nm}$ by a full-wavelength microplate reader (Molecular Devices, SpectraMax M5, Silicon Valley, USA). The effect of ARCSP on the survival rate of cervical cancer cells was evaluated.

\section{Lactate dehydrogenase (LDH) release assay for the evaluation of cytotoxicity}

The cells were incubated with ARCSP in 96-well plates for $48 \mathrm{~h}$, and LDH activity was detected according to the instructions of the LDH release kit (Dojindo, CK 12). The absorbance was measured at $490 \mathrm{~nm}$ by a fullwavelength multifunction microplate reader. Cervical cancer cell injury was assessed after ARCSP intervention based on LDH release.

\section{5-Ethynyl-2'-deoxyuridine glycoside (EdU) proliferation assay}

After incorporation of EDU, cell proliferation was measured using the BeyoClickTM EdU-488 Cell Proliferation Assay Kit (Beyotime, C0071S). The cells were fixed, permeabilized, and labeled with EdU according to the manufacturer's instructions after ARCSP treatment for $48 \mathrm{~h}$. The nuclei were stained with Hoechst 33342 (1 $\mu \mathrm{g} /$ $\mathrm{ml}$ ) for $10 \mathrm{~min}$ at room temperature. The proportion of cells showing EdU incorporation was measured under an inverted fluorescence microscope (Olympus, IX73, Tokyo, Japan).

\section{Cell colony formation assay}

Briefly, 1000 cells were cultured in 24-well plates and treated with ARCSP. After 14 days, the cells were fixed with $4 \%$ paraformaldehyde for $15 \mathrm{~min}$, stained with crystal violet for $15 \mathrm{~min}$, and washed three times. The number of colonies with a cell size $>1 \mathrm{~mm}$ was counted.

\section{Cell apoptosis}

Cells were cultured, treated for $48 \mathrm{~h}$, collected, washed with PBS, resuspended and incubated in FITC AnnexinV/PI solution (Biolegend, 640,914, USA) for apoptosis analysis. At least 10,000 live cells were analyzed on a flow cytometer (Beckman, Miami, USA).

\section{TUNEL assay}

The cells were cultured in 96-well plates, incubated with ARCSP for $48 \mathrm{~h}$, fixed in $4 \%$ paraformaldehyde and then permeabilized in $0.2 \%$ Triton X-100. TUNEL staining (Roche, 11,684,817,910, USA) was performed according to the manufacturer's instructions and observed under a 


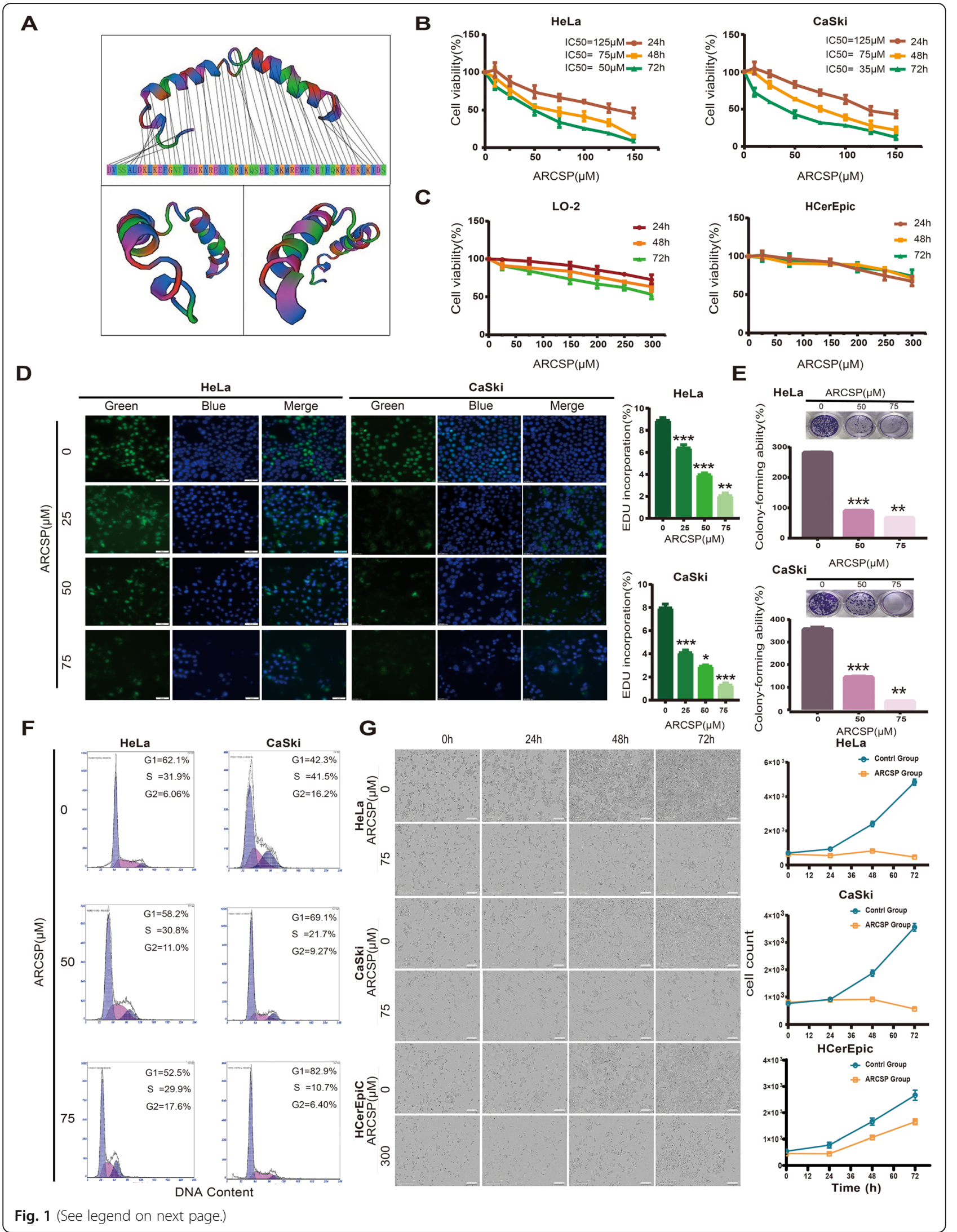


(See figure on previous page.)

Fig. 1 ARCSP inhibits the proliferation of cervical cancer cells and has low cytotoxicity in normal cells. a Model of the secondary structure of ARCSP. b Cervical cancer cell lines were treated with ARCSP $(0-150 \mu \mathrm{M})$ for 24-72 h, and cell viability was measured by the CCK8 assay. c Normal cell lines (LO-2 and HCerEpic cells) were treated with ARCSP (0-300 $\mu \mathrm{M})$ for 24-72 $\mathrm{h}$, and cell viability was measured by the CCK8 assay. $\mathbf{d}$ Cells were treated with ARCSP $(0-75 \mu \mathrm{M})$ for $48 \mathrm{~h}$, and the proliferation of cells was measured by the EdU proliferation assay. Scale bar $=50 \mu \mathrm{m}$. The histograms show the quantified EdU incorporation data, which were calculated using ImageJ software. e Cells were treated with ARCSP (0$75 \mu \mathrm{M})$ for 14 days, and clone-forming ability was determined by the cell colony formation assay. The histograms show the quantified results of the colony formation assay, which were calculated using ImageJ software. f After $48 \mathrm{~h}$ of treatment with ARCSP $(0-75 \mu \mathrm{M})$, cell cycle distribution was analyzed by FACS; the ratios of cells in G1, S, and G2/M phases are shown on the right. $\mathbf{g}$ After $72 \mathrm{~h}$ of continuous treatment with ARCSP $(75 \mu \mathrm{M}, 300 \mu \mathrm{M})$, the number of cells was significantly reduced. Scale bar $=300 \mu \mathrm{m}$. The data are expressed as the mean \pm SD; ${ }^{*} P<0.05,{ }^{* *} P<0.01$, ${ }^{* * *} P<0.001$. ns, not significant

fluorescence microscope (Leica, DMi8, Wetzlar, Germany).

\section{Cell cycle}

The cell cycle was evaluated by using PI (Becton Dickinson, 550,825, New Jersey, USA). Briefly, $2 \times 10^{5}$ cells were cultured in 6-well plates and incubated overnight (the serum was removed to synchronize the cells). After ARCSP treatment for $48 \mathrm{~h}$, the cells were collected, fixed in $70 \%$ ethanol overnight at $4{ }^{\circ} \mathrm{C}$, and then stained with $0.5 \mathrm{ml}$ of PI/RNase staining solution for $15 \mathrm{~min}$. DNA content was analyzed by flow cytometry to determine ratio of cells at each stage of the cell cycle. At least 20,000 viable cells were analyzed on a flow cytometer (Beckman).

\section{Measurement of ROS levels}

Cells were treated with ARCSP for $48 \mathrm{~h}$, the oxidationsensitive probe dichlorodihydrofluorescein diacetate (DCFH-DA, Beyotime, S0033) was added, and the cells were incubated for $30 \mathrm{~min}$ and then imaged under an inverted fluorescence microscope. To quantify the intensity of the probe, flow cytometry (Becton Dickinson) was used to detect changes in intracellular ROS levels.

\section{Measurement of the mitochondrial membrane potential} Cells were cultured in 96-well plates, incubated with ARCSP-FITC for $48 \mathrm{~h}$, and then washed with PBS. Then, $100 \mu \mathrm{L}$ MitoTracker Red CMXRos $(60 \mathrm{nM})$ was added for $30 \mathrm{~min}$ in a humidified incubator. The nuclei were stained with Hoechst $33342(1 \mu \mathrm{g} / \mathrm{ml})$ for $10 \mathrm{~min}$ at room temperature and observed under a fluorescence microscope.

\section{Intracellular ATP assay}

Cells were uniformly seeded in 96-well plates and treated with ARCSP for $48 \mathrm{~h}$. Then, the ATP level in the cells was detected according to the instructions of the Luminescent ATP detection assay kit (Abcam, Cambridge, MA, USA).

\section{Transmission electron microscopy}

Autophagosomes were observed by transmission electron microscopy (TEM). Cells were incubated with ARCSP for $48 \mathrm{~h}$, collected, fixed in $2.5 \%$ glutaraldehyde (pH 7.3-7.4) at $4{ }^{\circ} \mathrm{C}$ overnight and treated with $1 \%$ osmium tetroxide for $2 \mathrm{~h}$. Then, the samples were dehydrated in ethanol (70, 80, 90 and 95\%) and propylene oxide, embedded, cut into $50 \mathrm{~nm}$-sections, and stained with 3\% uranyl acetate and lead citrate. Images were taken under a transmission electron microscope (TOSHIBA, Tokyo, Japan).

\section{mRFP-GFP-LC3 puncta assay}

Cells were plated in a 24-well plate, transfected with mRFP-GFP-LC3 adenovirus (HanBio Technology, Shanghai, China) for $4 \mathrm{~h}$, incubated with ARCSP for $48 \mathrm{~h}$ and observed under a confocal microscope (Zeiss, LSM880). mRFP was used to label and track LC3. Attenuation of GFP expression indicated that lysosomes had fused with autophagosomes to form autophagolysosomes, and GFP was quenched due a change in the $\mathrm{pH}$, at which point only red fluorescence was detected. After microscopic imaging, the red and green fluorescence images were merged; the yellow puncta were considered autophagosomes $\left(\mathrm{RFP}^{+} \mathrm{GFP}^{+}\right)$, and the red puncta were considered autophagolysosomes $\left(\mathrm{RFP}^{+} \mathrm{GFP}^{-}\right)$. The intensity of autophagy flux was assessed by counting the number of yellow and red puncta. ARCSP treatment increased the numbers of yellow and red puncta, indicating that it increased autophagic flux; when the number of yellow puncta but not red puncta increased in the cells or when the numbers of yellow and red puncta decreased in the cells, autophagic flux was blocked.

\section{Lyso-Tracker Red staining}

Cells were cultured in 96-well plates, incubated with ARCSP-FITC for $48 \mathrm{~h}$, and then washed with PBS. Then, $100 \mu \mathrm{L}$ LysoTracker Red $(60 \mathrm{nM})$ was added, and the cells were incubated for $40 \mathrm{~min}$ in a humidified incubator. The nuclei were stained with Hoechst $33342(1 \mu \mathrm{g} / \mathrm{ml})$ for 10 min at room temperature, and the cells were observed under a fluorescence microscope. 


\section{AO staining}

Cells were treated with ARCSP for $48 \mathrm{~h}$, incubated with acridine orange (AO) $(1 \mu \mathrm{g} / \mathrm{ml})$ for $15 \mathrm{~min}$. The nuclei were stained with Hoechst $33342(1 \mu \mathrm{g} / \mathrm{ml})$ for $10 \mathrm{~min}$ at room temperature, and the cells were observed under a fluorescence microscope.

\section{Assessment of autophagy by immunostaining}

After $48 \mathrm{~h}$ of stimulation with ARCSP, cells were fixed with $4 \%$ paraformaldehyde for $20 \mathrm{~min}$ and permeabilized with $0.1 \%$ Triton-PBS for $15 \mathrm{~min}$. The cells were incubated with LC3B and p62 antibodies overnight at $4{ }^{\circ} \mathrm{C}$ on a horizontal shaker. Then, the cells were incubated with an Alexa Fluor ${ }^{\circ}$ 488conjugated goat anti-rabbit IgG secondary antibody and an Alexa Fluor ${ }^{\circ}$ 594-conjugated goat anti-mouse IgG secondary antibody for $1.5 \mathrm{~h}$ at room temperature, washed with PBS and stained with DAPI $(10 \mu \mathrm{g} / \mathrm{ml})$ for $10 \mathrm{~min}$. Photographs were taken under an inverted fluorescence microscope. Cell-induced autophagy was evaluated by observing LC3B and p62 staining, and the images were quantitatively assessed with ImageJ software.

\section{RNA extraction and quantitative real-time polymerase chain reaction $(\mathrm{PCR})$}

p62 RNA was extracted from HeLa and CaSki cells by using RNAiso Plus (Takara, 9109, Tokyo, Japan), and $1 \mu \mathrm{g}$ of total RNA was reverse transcribed using a PrimeScript RT kit (Takara, RR047A) to detect relative mRNA levels. Quantitative real-time PCR (Takara, RR820A) was performed on the Quantitative PCR System (Applied Biosystems 7500, California, USA). The Ct values obtained from different samples were compared using the $2^{-\Delta \Delta \mathrm{Ct}}$ method. GAPDH served as an internal reference gene. The sequences of primer pairs were as follows: human p62, forward primer: CCGTCTACAGGTGAACTC CAGTCC; reverse primer: AGCCAGCCGCCTTCAT CAGAG; human GAPDH, forward primer: CCCACTCC TCCACCTTTGAC; reverse primer: TCTTCCTCTT GTGCTCTTGC (Sangon Biotech).

\section{Short hairpin RNA (shRNA) transfection}

The shRNA sequence was as follows: human Atg7 (shAtg7): TTCTCCGAACGTGTCACGTAA (HanBio Technology). The cells were transfected with lentivirus expressing sh-Atg7 or sh-nc, and the knockdown efficiency of the target protein Atg7 was determined by Western blotting. Then, after treatment with ARCSP for $48 \mathrm{~h}$, the proliferation of the cells was detected by the CCK8 assay, colony formation assay and Western blotting.

\section{Western blotting}

Cells were lysed in RIPA buffer (Beyotime, P0013). The protein concentration was quantified by using the BCA Protein Assay Kit (Thermo Fisher Scientific Pierce, 23, 225, California, USA). The proteins were electrophoresed on 8-15\% SDS polyacrylamide gels and then transferred to PVDF membranes (Millipore, ISEQ00010 Burlington, USA). The membranes were placed in 5\% skim milk for $2 \mathrm{~h}$ at room temperature and incubated with antibodies overnight at $4{ }^{\circ} \mathrm{C}$. Finally, the membranes were incubated with a horseradish peroxidase (HRP)-conjugated antibody for $2 \mathrm{~h}$ at room temperature. Target proteins were detected by using an enhanced ECL kit (Millipore, WBKLS0100). GAPDH antibody was used as a control for whole-cell lysates.

\section{In vivo antitumour effect}

BALB/c immunodeficient nude mice $(\mathrm{Nu} / \mathrm{Nu})$ mice $(6-$ 8 weeks old) weighing 20-22 g were purchased from Beijing Weitong Lihua Experimental Animal Technology Co. Ltd. (China). The animal protocol performed in this study was approved by the Animal Care and Use Committee of the First Affiliated Hospital of Zhengzhou University. HeLa cells $\left(1 \times 10^{6}\right.$ cells $)$ were injected into the right axillae of the nude mice (five mice per group). When the tumor volume was $50 \mathrm{~mm}^{3}$, the mice were randomly divided into two groups: the control group and the ARCSP $(5 \mathrm{mg} / \mathrm{kg})$ treatment group. ARCSP was dissolved in $0.9 \%$ physiological saline. The control group was given the same concentration of physiological saline. ARCSP was administered continuously for 18 days by intraperitoneal injection. The tumor size and body weight of each mouse were measured every 3 days during ARCSP treatment. At the end of the experiment, the mice were sacrificed after anesthesia. The tumors were immediately fixed in $10 \%$ formalin and then embedded in paraffin. Tumor sections were selected for immunohistochemical staining of proteins including Ki67, PCNA, LC3B, and Bax. Images were taken under a microscope (Olympus BX51).

\section{Statistical analysis}

Data were obtained from at least three independent experiments and are presented as the mean \pm SD. Statistical analysis was performed using GraphPad Prism software 7.0 (GraphPad Software, La Jolla, CA, USA). The nonparametric Mann-Whitney test (for data that were not normally distributed) or Student's t-test (for data that were normally distributed) was used to measure the differences between the two groups. One-way analysis of variance (ANOVA) was used for comparisons between multiple sets of quantitative data. Pairwise comparisons were performed using the LSD-t test. $P<0.05$ was considered statistically significant. 


\section{Results}

\section{ARCSP inhibits the proliferation of cervical cancer cells} and has low cytotoxicity in normal cells

To study the effects of ARCSP on the growth of human cervical cancer cells, we used HCerEpiC, LO-2, HeLa and CaSki cells. The CCK8, EdU and cell colony formation assays were used to observe the effects of ARCSP on cell proliferation. Our results indicated that ARCSP significantly inhibited the growth of HeLa cells $\left(\mathrm{IC}_{50}=50-125 \mu \mathrm{M}\right)$ and CaSki cells $\left(\mathrm{IC}_{50}=35-\right.$ $125 \mu \mathrm{M}$ ) after $24-72 \mathrm{~h}$ of treatment (Fig. 1b) and that the growth of cervical cancer cells was reduced in a dose-dependent manner. Moreover, ARCSP did not cause significant toxicity to normal epithelial cells, at a dose $\left(\mathrm{IC}_{50}=300 \mu \mathrm{M}\right)$ that was 4 times more than that used in the experiments $\left(\mathrm{IC}_{50}=75 \mu \mathrm{M}\right.$; Fig. 1c). The number of living cells that showed by EdU incorporation was significantly reduced by ARCSP in a dose-dependent manner (Fig. 1d). In addition, the cell colony formation experiments showed that the colony-forming ability of the cells was significantly inhibited after ARCSP treatment (Fig. 1e). Cell proliferation was arrested at G2/M phase in HeLa cells and at G0/G1 phase in CaSki cells (Fig. 1f). In addition, quantitative live-cell imaging (Essen, IncuCyteZOOM, USA) showed a time-dependent decrease in the number of cells after treatment with $75 \mu \mathrm{M}$ ARCSP (Fig. $1 \mathrm{~g})$. These results indicated that ARCSP has an inhibitory effect on cervical cancer cells. ARCSP has an $\mathrm{IC}_{50}=75 \mu \mathrm{M}$ in HeLa and CaSki cells. Therefore, the concentration of ARCSP used in the subsequent experiments was $75 \mu \mathrm{M}$.

\section{ARCSP induces apoptosis of cervical cancer cells}

Next, we investigated how ARCSP-induced cervical cancer cell death is regulated. First, HeLa and CaSki cells were treated with different concentrations of ARCSP for $48 \mathrm{~h}$. The TUNEL assay and flow cytometry results showed that ARCSP induced apoptosis (Fig. 2a, Fig. S2A). Furthermore, the LDH release assay also revealed that ARCSP damaged the integrity of the plasma membrane in HeLa and CaSki cells (Fig. 2b). In addition, the mitochondrial membrane potential assay showed that ARCSP exerted a prominent apoptotic effect on cervical cancer cells and induced mitochondrial dysfunction (Fig. 2c). Furthermore, cleaved-caspase8, cleaved-caspase9, Bax, Bid, and P21 accumulated upon ARCSP treatment (Fig. 2d). We also investigated ARCSP-induced production of ROS in HeLa and CaSki cells. ARCSP increased the levels of ROS in cells, as determined by flow cytometry and fluorescence labeling (Fig. S2B, C). NAC is an ROS scavenger that significantly reduces ROS production in cells, but we observed that cotreatment with NAC and ARCSP did not reverse the inhibition of cell proliferation (Fig. S2D). The results indicated that ARCSP damage mitochondria, leading to ROS accumulation, which may have been a cause of cell death.

We also cotreated HeLa and CaSki cells with ARCSP and a series of inhibitors for $48 \mathrm{~h}$. Z-VAD-FMK is a classical caspase inhibitor, but the inhibition of cervical cancer cell proliferation was not reversed by cotreatment with Z-VAD-FMK (Fig. 2e). Interestingly, cotreatment with ARCSP and CQ induced more cell death than treatment with ARCSP alone, indicating that autophagy might also be involved in ARCSP-induced cell death.

\section{ARCSP induces autophagy, and the AMPK/mTOR signaling pathway may be involved in ARCSP-induced autophagy}

Next, we investigated whether ARCSP induces autophagy in HeLa and CaSki cells. ARCSP treatment induced the transformation of LC3B-I to LC3B-II and upregulated the expression of LC3B-II and Atg7 (Fig. 3a). Fortunately, we were able to observe the bilayer membrane of autophagosomes using TEM (Fig. 3b). More autophagosome aggregation was observed in the ARCSP-treated group than in the untreated control group. These results demonstrate that ARCSP can induce autophagy in cells.

As a key protein of cell growth, mTOR plays an important role in cell metabolism and proliferation. The AMPK/mTOR signaling pathway is the main autophagyinitiating pathway. ARCSP can damage mitochondria and decrease the mitochondrial transmembrane potential (Fig. 2c), leading to decreased production of ATP. We measured ATP levels in cells treated with ARCSP. As expected, compared to untreated control cells, ARCSP-treated cells showed a dose-dependent decrease in ATP production (Fig. 3c). Therefore, we speculate that AMPK might play a critical role in ARCSP-induced autophagy.

Immunoblotting showed that ARCSP positively regulated AMPK and its downstream protein Raptor (Fig. S2E), thereby inhibiting the activity of mTOR. Furthermore, the expression of p70s6k, another downstream protein that plays a key role in regulating autophagy, was significantly inhibited in $\mathrm{HeLa}$ and CaSki cells (Fig. 3d). Dorsomorphin (CC), an inhibitor of AMPK, significantly inhibited the expression of the proteins LC3B-II and AMPK in ARCSP-treated cells (Fig. 3e). These data suggest that ARCSP induces autophagy by activating the AMPK/mTOR pathway in HeLa and CaSki cells.

\section{ARCSP blocks autophagic flux}

The accumulation of autophagosomes (increased levels of LC3B-II) by ARCSP treatment may represent either an increase in the number of autophagosomes or blockade of autophagolysosome formation through the fusion 


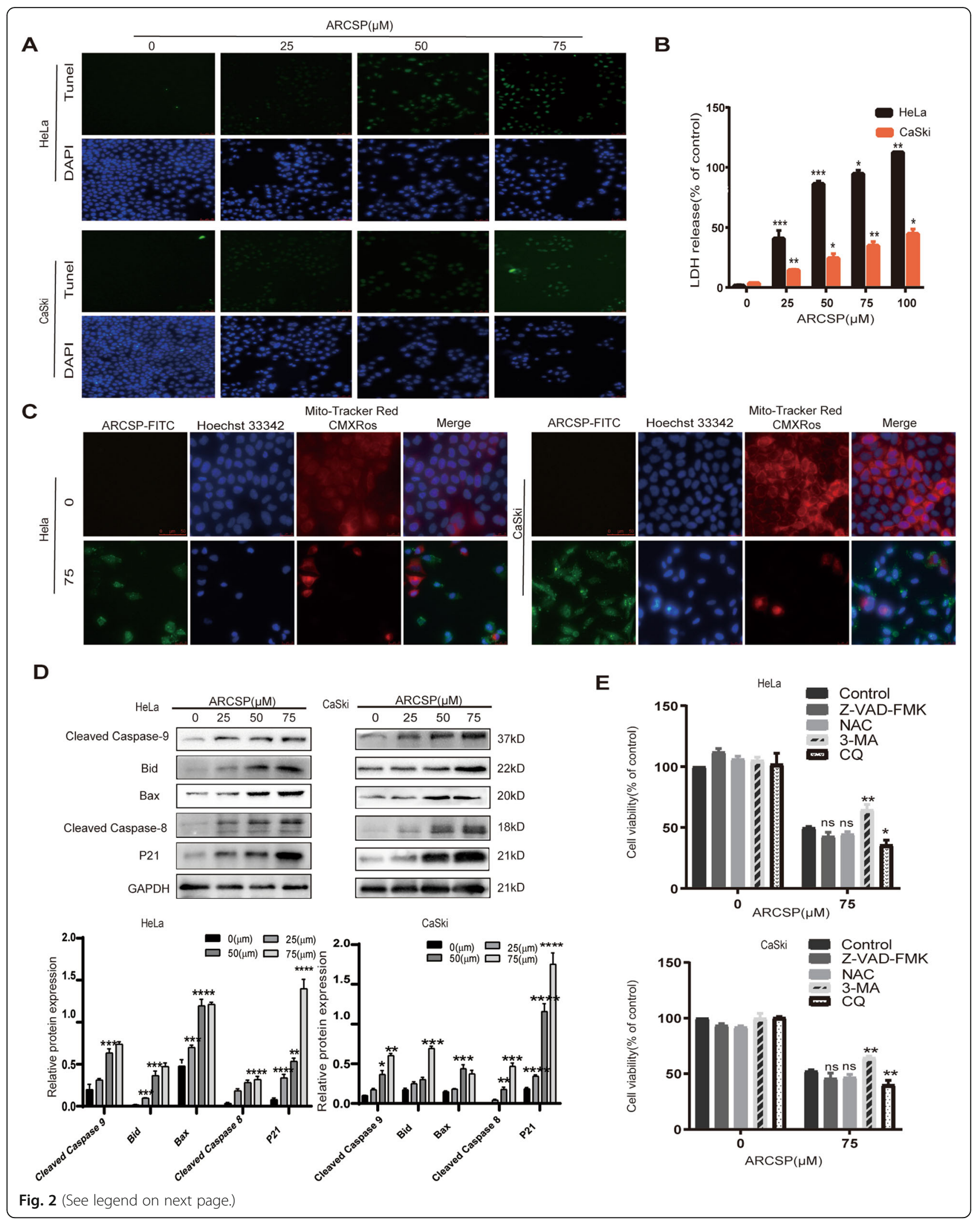


(See figure on previous page.)

Fig. 2 ARCSP induces apoptosis of cervical cancer cells. a Cells were treated with ARCSP (0-75 $\mu \mathrm{M})$ for $48 \mathrm{~h}$, and the apoptosis index was determined by the TUNEL assay. Scale bar $=50 \mu \mathrm{m}$. b Cells were treated with ARCSP $(0-100 \mu \mathrm{M})$ for $48 \mathrm{~h}$, and cell membrane damage was detected by the LDH release assay. c Cells were treated with ARCSP $(75 \mu \mathrm{M})$ for $48 \mathrm{~h}$, and the mitochondrial membrane potential was determined by MitoTracker Red staining, Hoechst 33342 (blue) was used to stain the nuclei. Scale bar $=25 \mu \mathrm{m}$. $\mathbf{d}$ Cells were treated with ARCSP (0-75 $\mu$ M) for $48 \mathrm{~h}$, and the expression levels of cleaved-caspase 9, Bid, Bax, cleaved-caspase 8, and P21 were detected. e Cells were cotreated with ARCSP and Z-VAD-FMK $(5 \mu \mathrm{M})$, NAC $(5 \mu \mathrm{M}), 3-\mathrm{MA}(20 \mu \mathrm{M})$ or CQ $(20 \mu \mathrm{M})$ for $48 \mathrm{~h}$, and cell viability was determined by the CCK8 assay. The data are expressed as the mean $\pm \mathrm{SD} ;{ }^{*} P<0.05,{ }^{* *} P<0.01,{ }^{* * *} P<0.001$. ns, not significant

of autophagosomes and lysosomes. Next, we evaluated autophagic flux to clarify whether ARCSP affects the entire process of autophagy. It is well known that the p62 protein is an autophagic substrate, and a reduction in the level of p62 is considered a marker of increased autophagic flux. ARCSP treatment increased the expression of p62 in a dose-dependent manner in HeLa and CaSki cells (Fig. 4a). In addition, there was no significant change in the mRNA level of p62 after $48 \mathrm{~h}$ of treatment with ARCSP, indicating that the increase in p62 occurred at the protein level (Fig. 4b). In addition, ARCSP treatment resulted in an accumulation of p62 points (Fig. 4c). Moreover, we investigated the colocalization of endogenous P62 puncta and LC3B (an autophagosome marker) puncta in ARCSP-treated cells. ARCSP treatment resulted in the accumulation of p62 puncta and increased colocalization of these puncta with LC3B puncta (Fig. S3). These results indicate that ARCSP can induce autophagosome accumulation but may block autophagic flux.

We transfected HeLa and CaSki cells with the mRFPEGFP-LC3 adenovirus to monitor the synthesis of autophagosomes and autophagosome-lysosomal fusion. Autophagosomes were indicated by yellow puncta, and autophagolysosomes were indicated by red puncta (GFP fluorescent protein is sensitive to acidity). When autophagosomes fused with lysosomes, GFP fluorescence was quenched, and only mRFP (red) was detected. After ARCSP or chloroquine (CQ) treatment, the number of autophagosomes was greater than the number of autophagolysosomes. In addition, rapamycin (Rapa)-induced autophagic flux was blocked by ARCSP. These results strongly indicate that ARCSP blocks autophagic flux in HeLa and CaSki cells and that ARCSP-induced autophagic flux inhibition is independent of the mechanisms of ARCSP-initiated autophagy (Fig. 4d).

\section{ARCSP-mediated cytotoxic death due to excessive accumulation of autophagosomes}

To confirm the role of ARCSP in blocking autophagic flux in HeLa and CaSki cells, we used an autophagosome formation inhibitor (early autophagy inhibitor, 3-MA) and an autophagosome-lysosome fusion inhibitor (late autophagy inhibitor, CQ). We found that 3-MA significantly reversed the change in the LC3B- II/ I ratio induced by treatment with ARCSP in HeLa and CaSki cells, whereas CQ did not have significant effects on the ratio of LC3B- II/ I (Fig. 5a, b). In addition, the combination of ARCSP and 3-MA treatment reversed the inhibitory effects of ARCSP on the proliferation and colony-forming ability of the cells.

However, the combination of ARCSP and CQ had enhanced the inhibitory effects of ARCSP on the proliferation and colony-forming ability of the cells (Fig. 5c, d, e, f). Consistently, the TUNEL assay showed that the combination of ARCSP and CQ had a significant apoptotic effect on cells (Fig. 5g). These data suggest that ARCSP can block the fusion of autophagosomes and lysosomes, causing the excessive accumulation of autophagosomes and thus enhancing cytotoxic death of HeLa and CaSki cells.

\section{ARCSP treatment inhibits lysosomal activity}

Next, we explored whether the autophagosome and lysosome fusion process is impaired. We investigated whether there endogenous LC3B puncta were colocalized with LAMP1 (a lysosome marker) in ARCSPtreated HeLa and CaSki cells. ARCSP treatment resulted in fewer LAMP1 puncta and decreased colocalization of LAMP1 puncta with LC3B puncta (Fig. 6a), indicating that the fusion of autophagosomes and lysosomes was blocked.

To test whether ARCSP adversely affects lysosomal function, we examined the $\mathrm{pH}$ of the lysosomes using acridine orange (AO) and Lyso-Tracker Red staining. These dyes are fluorescent dyes that accumulate in acidic spaces, such as lysosomes, and emit red light. Red fluorescence was decreased in ARCSP-treated cells compared to untreated control cells (Fig. 6b, Fig. S4A). These results indicate that ARCSP-induced inhibition of autophagy is dependent on changes in lysosomal $\mathrm{pH}$.

Furthermore, we examined the expression of Rab7, LAMP1 and LAMP2. Immunoblotting showed that the expression of these proteins were decreased by ARCSP in a dose-dependent manner (Fig. 6c), indicating that ARCSP disrupted lysosomal membrane function to block autophagic flux. Cathepsin D (CTSD) is a lysosomal cathepsin that is involved in lysosomal nonspecific protein degradation. As expected, after ARCSP treatment, CTSD expression was downregulated (Fig. 6c), 


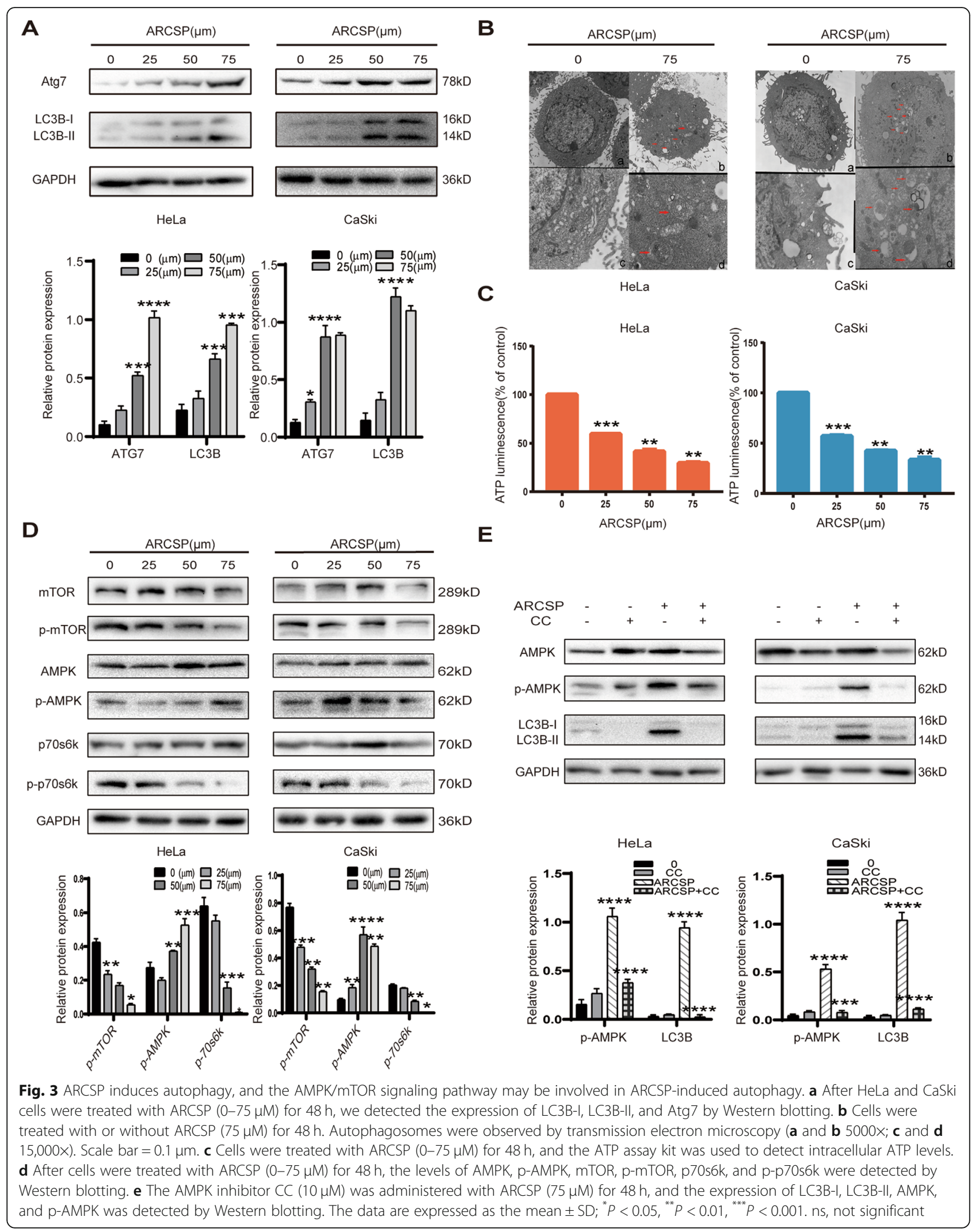




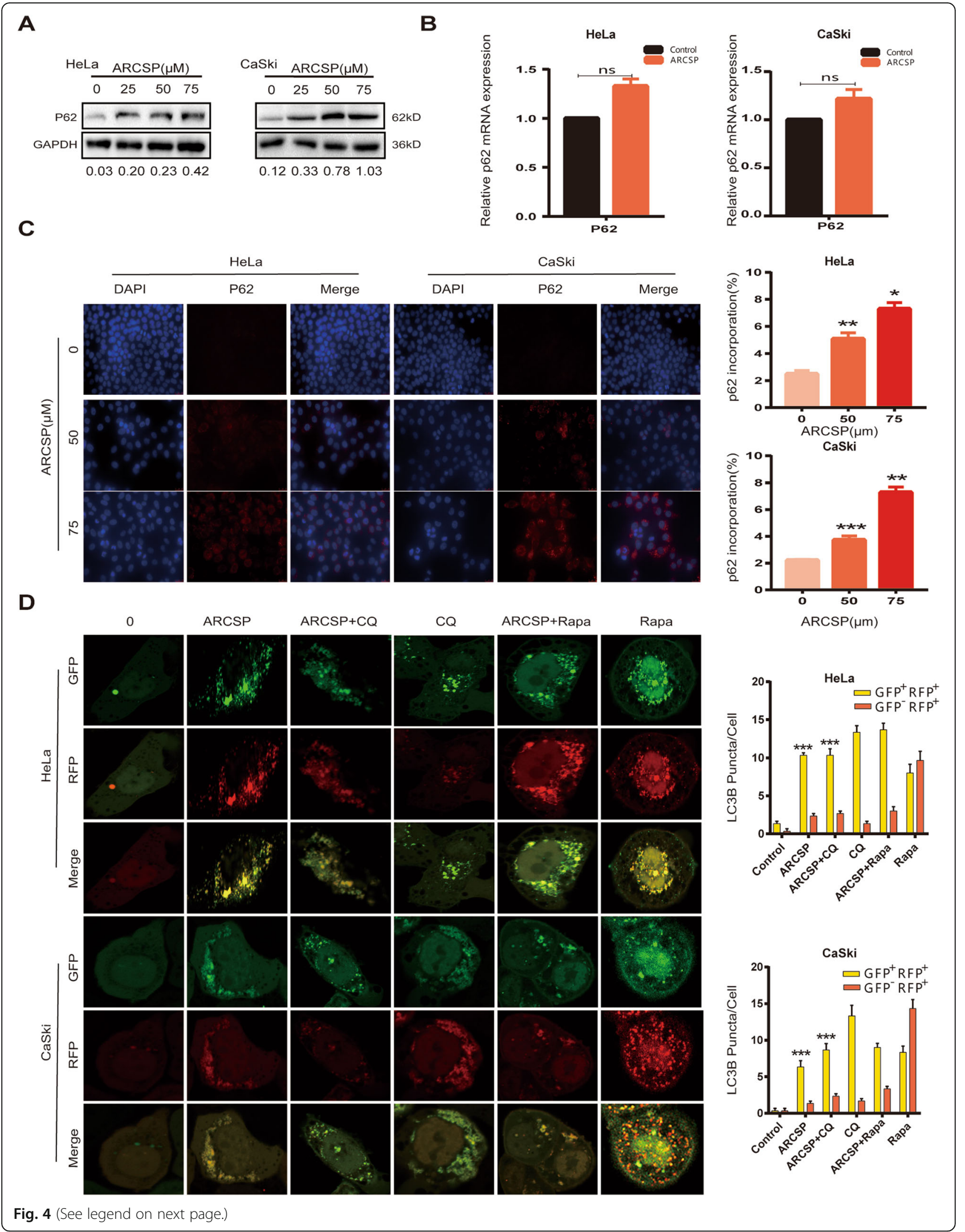


(See figure on previous page.)

Fig. 4 Autophagy flux is blocked by ARCSP. a Cells were treated with ARCSP $(0-75 \mu \mathrm{M})$ for $48 \mathrm{~h}$, and the level of p62 was detected by Western blotting. b p62 mRNA expression after treatment with ARCSP $(75 \mu \mathrm{M})$. c Cells were treated with ARCSP $(0-75 \mu \mathrm{M})$ for $48 \mathrm{~h}$, immunolabeling with p62 (594 red) antibodies. DAPI (blue) was used to stain the nuclei, and the cells were photographed under a fluorescence microscope. Scale $\mathrm{bar}=25 \mu \mathrm{m}$. The histograms showed quantification results of p62 localization which were calculated using ImageJ software. $\mathbf{d}$ Cells were transfected with the mRFP-EGFP-LC3 adenovirus, cocultured with ARCSP $(75 \mu \mathrm{M})$ and Rapa $(100 \mathrm{~nm})$ or CQ $(20 \mu \mathrm{M})$ for $48 \mathrm{~h}$, and analyzed by confocal microscopy. Scale bar $=10 \mu \mathrm{m}$. The histograms show the quantification of yellow and red puncta, which was performed using ImageJ software. The data are expressed as the mean \pm SD; ${ }^{*} P<0.05,{ }^{* * *} P<0.01,{ }^{* * *} P<0.001$. ns, not significant

indicating that ARCSP inhibited lysosomal cathepsin activity, resulting in the accumulation of autophagosomes. In addition, ARCSP treatment resulted in an accumulation of CTSD points (Fig. S4B).

To further investigate the relationship between autophagic flux blockade and ARCSP-induced cell death, we constructed Atg7 knockout cells using shRNA technology and then treated them with ARCSP. Cell viability was measured using the CCK8 assay and the colony formation assay. The data indicated that Atg7 knockout reversed the inhibitory effect of ARCSP on cell proliferation (Fig. 6d, e) and attenuated the expression level of LC3B-II (Fig. 6f), indicating that ARCSP-induced cell death was associated with an increase in the number of autophagosomes. Overall, these data suggest that ARCSP-induced autophagic flux inhibition contributes to cell death of HeLa and CaSki cells.

\section{ARCSP-induced autophagy exerts antitumor effects in a HeLa cell xenograft model}

HeLa cells are more sensitive than other cells to ARCSP in vitro. Therefore, a xenograft model established by using HeLa cells was used to investigate the antitumor activity of ARCSP in vivo. On the 7th day, nude mice were randomly divided into two groups: the control group (intraperitoneally injected with saline) and the treatment group (intraperitoneally injected with ARCSP, $10 \mathrm{mg} / \mathrm{kg}$ ). Tumors grew more slowly in the ARCSP treatment group than in the control group (Fig. 7a, b). After 18 days of treatment, the nude mice were sacrificed. The final tumor weight of the ARCSP-treated group was significantly different from that of the control group (Fig. 7c). The tumor size of the control group gradually increased with time (Fig. 7d). No change in body weight was observed after ARCSP treatment (Fig. 7a), indicating that ARCSP had almost no toxic effects in vivo.

A portion of the tumor tissue was snap frozen for Western blotting, and another portion was fixed for immunohistochemical staining. Consistent with our in vitro findings, the results showed that the expression of LC3B-II/I and Atg7 was increased in the treatment group compared with the control group (Fig. 7e), indicating that autophagosome accumulation was also induced in vivo. Immunohistochemical analysis revealed that compared with tissues from the control group, tissues from the ARCSP-treated group showed an increase in LC3B and Bax expression and a decrease in Ki67 and PCNA expression (Fig. 7f), further confirming the increase in the number of autophagosomes and the inhibition of proliferation.

\section{Discussion}

Recently, autophagy has emerged as a promising target for cancer treatment, and induction of autophagyassociated cytotoxic death through blockade of autophagic flux has been increasingly recognized as a novel cancer therapeutic strategy [19-21]. In the present study, we indicated that ARCSP has an effective antitumor effect on cervical cancer cells. ARCSP inhibited the growth of cells by inhibiting cell proliferation and inducing apoptosis. Interestingly, we found that ARCSP was a potent autophagy regulator in cells. ARCSP initiates autophagy by activating AMPK/mTOR signaling and impairs autophagic flux through inhibiting lysosomal activity, leading to the accumulation of nonfused autophagolysosomes in cells. Moreover, our findings indicated that the accumulation of nonfused autophagolysosomes by ARCSP enhanced cytotoxic death. We demonstrated for the first time that ARCSP can induce cytotoxic death through blocking autophagic flux and inducing the accumulation of nonfused autophagosomes.

Autophagy is a highly conserved catabolic process though which unnecessary substances or dysfunctional cellular components are captured and degraded in autophagolysosomes for recycling [22]. Autophagy has two functions in cancer therapy [23-25]. On the one hand, autophagy may induce cell death [26, 27]; on the other hand, autophagy may protect cells against external factors, such as drug resistance $[28,29]$. In the present study, we demonstrated that ARCSP can induce autophagosome synthesis. However, due to the lysosome dysfunction induced by ARCSP, autophagosomes and lysosomes cannot be normally fused and degraded. Blockade of the early initiation of autophagy reversed ARCSP-induced cervical cancer proliferation inhibition, while inhibiting the fusion of autophagosomes and lysosomes aggravated ARCSP-induced apoptosis.

Our results indicate that ARCSP inhibits the proliferation of cervical cancer cells and induces apoptosis in vitro and in vivo (Figs. 1, 2 and 7). Moreover, we 


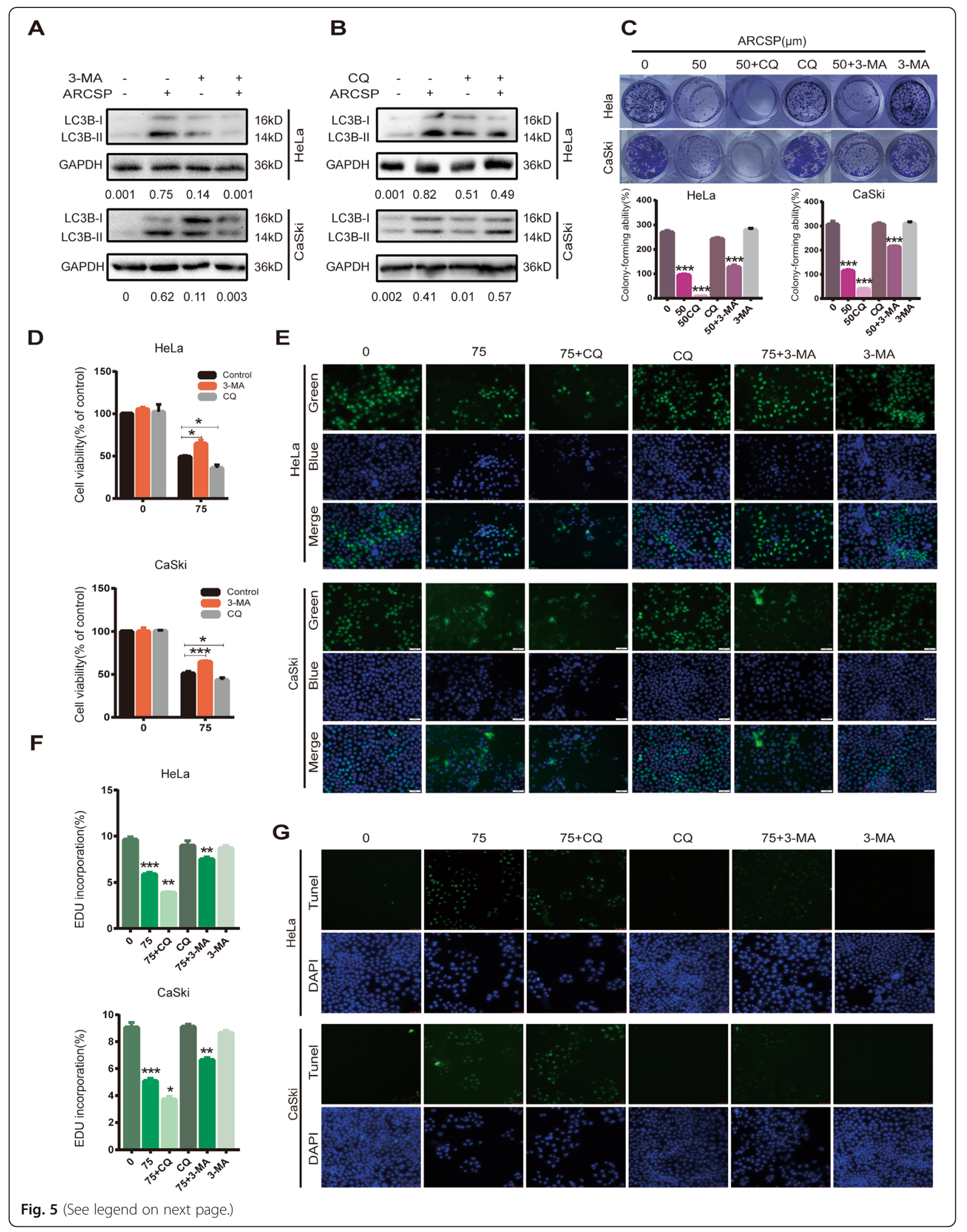


(See figure on previous page.)

Fig. 5 ARCSP-induced cytotoxic death may be associated with the accumulation of autophagosomes. a-b Cells were treated with ARCSP (75 $\mu M$ ) and 3-MA $(20 \mu \mathrm{M})$ or CQ $(20 \mu \mathrm{M})$ for $48 \mathrm{~h}$, and the level of LC3B- II/ I was detected by Western blotting. c Cells were treated with ARCSP (50 $\mu \mathrm{M})$ and 3-MA $(20 \mu \mathrm{M})$ or CQ $(20 \mu \mathrm{M})$ for 14 days, and the ability of the cells to proliferate was examined by the cell colony formation assay. The histograms show the quantified results of the colony formation assay, which were calculated using ImageJ software. $\mathbf{d}$-g Cells were treated with ARCSP $(75 \mu \mathrm{M})$ and 3-MA $(20 \mu \mathrm{M})$ or CQ $(20 \mu \mathrm{M})$ for $48 \mathrm{~h}$. d Cell viability was analyzed by the CCK8 assay. e The cell proliferation rate was measured by the EdU assay, and the cells were photographed under a fluorescence microscope. Scale bar $=50 \mu \mathrm{m}$. $\mathbf{f}$ The histograms show the quantified results of the EdU assay, which were calculated using ImageJ software. $\mathbf{g}$ The apoptosis index was determined by the TUNEL assay, and the cells were photographed under a fluorescence microscope. Scale bar $=50 \mu \mathrm{m}$. The data are expressed as the mean \pm SD; ${ }^{*} P<0.05,{ }^{* *} P<$ $0.01,{ }^{* * *} P<0.001$. ns, not significant

observed an increase in the number of autophagosomes by electron microscopy (Fig. 3b). ARCSP induced high expression of p-AMPK, p-raptor, LC3B-II, atg7, and $\mathrm{p} 62$ and low expression of $\mathrm{p}$-mTOR and $\mathrm{p}$ p70s6k in cervical cancer cells (Figs. 3 and 4a). However, the p62 protein is an autophagy substrate that binds to LC3B-II in autophagosomes and is degraded after the formation of autophagolysosomes [30]. The observed increase in P62 protein expression indicated that autophagic flux was blocked (Fig. 4c, d). In addition, our further experiments showed that blocking autophagy flux strongly inhibited cell proliferation and enhanced cell death (Fig. 5). Given that ARCSP treatment leads to the accumulation of autophagosomes (increased levels of LC3B-II), this may represent either an increase in the number of autophagosomes or blockade of the formation of autophagolysosomes through the fusion of autophagosomes and lysosomes [31]. We assumed that ARCSP can increase the number of autophagosomes in cells by increasing autophagosome formation and blocking autophagolysosomal degradation. Our results confirmed that ARCSP induced an increase in lysosomal pH (Fig. 6b, Fig. S4A) and inactivation of CTSD (Fig. 6c), which affected lysosomal function. We demonstrated that ARCSP blocked autophagic flux, leading to the accumulation of nonfusion autophagosomes and enhancement of cell death. Therefore, we identified ARCSP as a novel lethal nonfused autophagosome inducer with low cytotoxicity to normal cells (Fig. 1c).

As a key cellular energy sensor, AMPK plays an important role in activating autophagy by inhibiting the activity of mTOR [32]. In addition to initiating autophagy, AMPK also plays an important role in the late stages of autophagy. On the one hand, AMPK can increase the ATP level in cells to promote autophagic degradation and maintain homeostasis; on the other hand, when intracellular nutrients are consumed excessively, negative feedback by AMPK inhibits autophagy because autophagy requires a sufficient amount of ATP to complete this complex membrane-dependent process [33-36]. Furthermore, the application of the AMPK inhibitor CC combined with ARCSP treatment significantly reversed the expression of LC3B-II (Fig. 3e), indicating that activation of AMPK caused autophagosome formation after ARCSP treatment.

Autophagy is a basic catabolic process during which damaged cellular tissues or dysfunctional proteins are engulfed by autophagosomes, which then fuse with lysosomes to mediate degradation to maintain cell homeostasis [37]. Lysosomes are considered the degradation centers of most eukaryotic cells [38, 39]. Lysosomal acidification, lysosomal transport, fusion of lysosomes with late endosomes or autophagosomes, and maturation of lysosomal proteases are essential for the maintenance of normal lysosomal physiology. Therefore, inhibition of lysosomal and autophagolysosomal functions severely impairs autophagic flux [40]. Our results indicated that after treatment with ARCSP, lysosomes and autophagosomes could not fuse properly, resulting in the accumulation of nonfused autophagosomes (Fig. 4d). In addition, ARCSP treatment increased the lysosomal $\mathrm{pH}$ (Fig. 6b, Fig. S4A) and downregulated the expression of LAMP1, LAMP2, Rab7, and CTSD (Fig. 6c), indicating that it severely affected the lysosomal function. Rab7, LAMP1 and LAMP2 are key membrane proteins on lysosomes and play important roles in maintaining the normal physiological function of lysosomes. CTSD is a lysosomal cathepsin that is involved in nonspecific protein degradation in lysosomes. Inhibition of CTSD function leads to massive accumulation of nonfused autophagosomes [41]. It has been confirmed that blockade of autophagic flux can cause the accumulation of dysfunctional proteins or damaged organelles, which can be fatal for cancer cells [40]. Notably, the effects of ARCSP were similar to those of $C Q$, which inhibits autophagosome-lysosome fusion. This is consistent with some recent studies showing that disruption of the late stage of autophagy leads to excessive accumulation of nonfused autophagosomes and has the potential to turn autophagy into a destructive process, resulting in fatal toxic effects on cells [30, 31].

Autophagy inhibitors have been shown to be useful adjuvants for many antitumor therapies in vivo [42]. The combination of CQ or its derivatives and chemotherapeutics has been used in phase 1 and phase 2 clinical trials for a variety of tumors [43, 44]. Therefore, we chose cisplatin (CDDP), a widely used chemotherapy drug for 


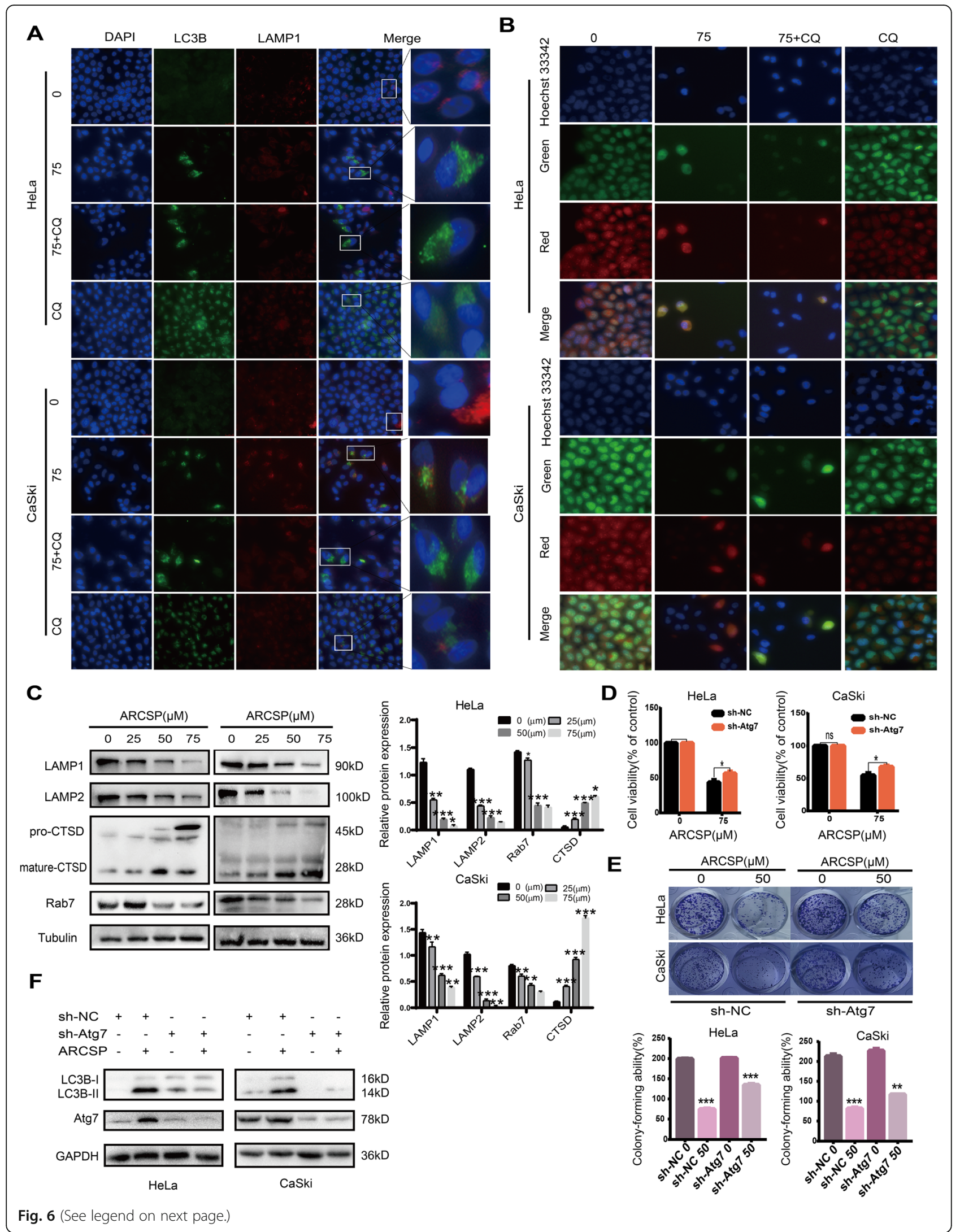


(See figure on previous page.)

Fig. 6 ARCSP may have a cytotoxic effect by affecting the function of lysosomes. a Cells were treated with ARCSP (75 $\mu \mathrm{M})$ for $48 \mathrm{~h}$, and the colocalization of LC3B (488 green) and LAMP1 (594 red) was assessed. DAPI (blue) was used to stain the nuclei, and the cells were photographed under a fluorescence microscope. Scale bar $=25 \mu \mathrm{m}$. b Cells were treated with ARCSP $(75 \mu \mathrm{M})$ or CQ $(20 \mu \mathrm{M})$ for $48 \mathrm{~h}$, stained with AO for $10 \mathrm{~min}$, Hoechst 33342 (blue) was used to stain the nuclei, and photographed under a fluorescence microscope. Scale bar $=25 \mu \mathrm{m}$. $\mathbf{c}$ Cells were treated with ARCSP $(0-75 \mu \mathrm{M})$ for $48 \mathrm{~h}$, and the levels of Rab7, LAMP1, LAMP2 and CTSD were detected by Western blotting. $\mathbf{d}$ Cells were transfected with sh-Atg7 and treated with ARCSP $(75 \mu \mathrm{M})$ for $48 \mathrm{~h}$, and cell viability was analyzed by the CCK8 assay. e Cells were transfected with sh-Atg7 and treated with $\operatorname{ARCSP}(50 \mu \mathrm{M})$ for 14 days, and the cell colony formation assay was used to evaluate cell proliferation. The histograms show the quantified results of the colony formation assay, which were calculated using ImageJ software. $\mathbf{f}$ Cells were treated with ARCSP (75 $\mu \mathrm{M})$ for $48 \mathrm{~h}$, and the expression of LC3B-I and LC3B-II was detected by Western blotting. The data are expressed as the mean \pm SD; ${ }^{*} P<0.05,{ }^{* *} P<0.01,{ }^{* * *} P<$ 0.001. ns, not significant

cervical cancer. The results of the CCK8 assay showed that ARCSP enhanced the lethality of low doses of $\operatorname{CDDP}(2.5-10 \mu \mathrm{M})$ and that lethality increased in an ARCSP dose-dependent manner. The survival rates of HeLa and CaSki cells following treatment with low-dose cisplatin $(2.5 \mu \mathrm{M})$ for $48 \mathrm{~h}$ were $69.71 \pm 0.99 \%$ and
$73.30 \pm 2.72 \%$, respectively. After treatment with low doses of ARCSP $(50 \mu \mathrm{M})$ for $24 \mathrm{~h}$, the survival rates of HeLa and CaSki cells were only $46.15 \pm 2.33 \%$ and $58.28 \pm 2.40 \%$, respectively (Fig. S5A-D). Therefore, the combination of ARCSP and chemotherapeutic drugs needs to be further studied.

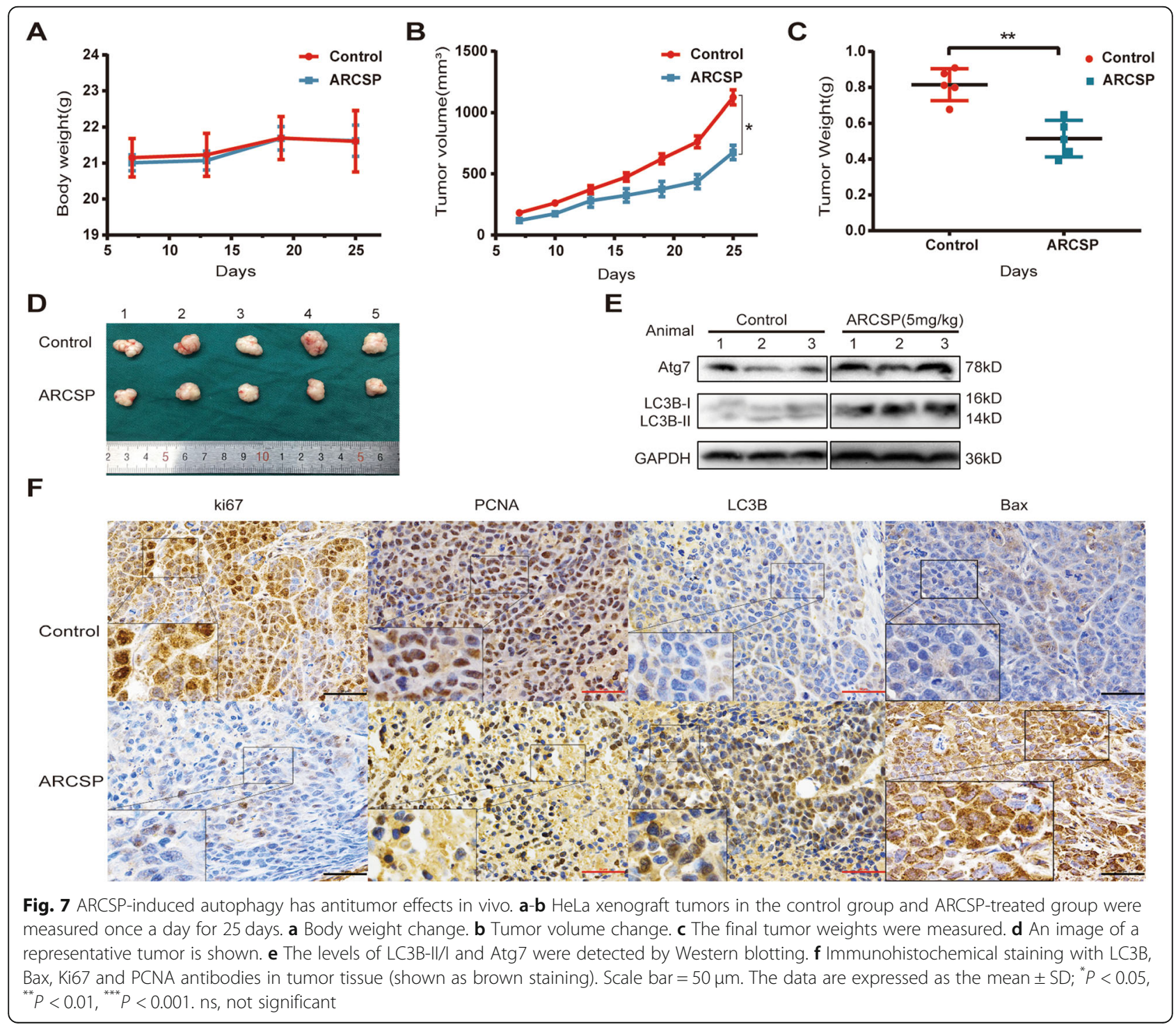




\section{Conclusion}

In summary, we discovered a novel mechanism of ARCSP-induced cervical cancer cell death and demonstrated that ARCSP-mediated inhibition of autophagic flux is key to the toxic death of cervical cancer cells. Mechanistic studies showed that ARCSP increased the number of nonfused autophagosomes in two ways: on the one hand, ARCSP induced apoptosis through mitochondrial dysfunction and initiated autophagy by activating the AMPK/mTOR signaling pathway; on the other hand, ARCSP impaired endosome maturation and lysosomal cathepsin activity to block autophagic flux, resulting in the accumulation of nonfused autophagosomes and thus leading to cytotoxic death. Identifying natural compounds that regulate autophagy may be an effective method for identifying novel autophagy inhibitors and lead compounds for cancer treatment [37, 45, 46]. Our results indicate that ARCSP can be used as an autophagy-targeted drug and low-dose chemotherapy adjuvant for cervical cancer with great research and application potential.

\section{Supplementary information}

Supplementary information accompanies this paper at https://doi.org/10. 1186/s13046-020-01701-z.

Additional file 1: Figure S1. ARCSP was detected by HPLC and MS. (A) After synthesis, ARCSP was subjected to HPLC. Pure ARCSP was observed at a retention time of $11.962 \mathrm{~min}$; the proportion of this peptide was 95.3198\%. (B) The evidence of identity based on mass spectral characterization.

Additional file 2: Figure S2. ARCSP induced cell apoptosis and increased intracellular ROS levels in cells. (A) Cells were treated with $\operatorname{ARCSP}(0-75 \mu \mathrm{M})$, the ratio of cell apoptosis was determined by flow cytometry. (B) Cells were cotreated with ARCSP $(75 \mu \mathrm{M})$ and NAC $(5 \mu \mathrm{M})$ for $48 \mathrm{~h}$ and incubated with $1 \mathrm{~mL}$ of serum-free medium containing DCFH-DA for $30 \mathrm{~min}$. The amount of ROS produced was measured under a fluorescence microscope. Scale bar $=25 \mu \mathrm{m}$. The histograms show the quantified results of ROS localization, which were calculated using ImageJ software. (C) Cells were cotreated with ARCSP $(75 \mu \mathrm{M})$ and NAC $(5 \mu \mathrm{M})$ for $48 \mathrm{~h}$ and incubated with $1 \mathrm{~mL}$ of serum-free medium containing DCFH-DA for 30 min. ROS production was determined by flow cytometry. (D) Cells were cotreated with ARCSP $(75 \mu \mathrm{M})$ and NAC $(5 \mu \mathrm{M})$ for 14 days, and clone-forming ability was determined by the cell colony formation assay. (E) After HeLa and CaSki cells were treated with ARCSP $(0-75 \mu \mathrm{M})$ for $48 \mathrm{~h}$, we detected the expression of Raptor and p-Raptor by Western blotting. The data are expressed as the mean $\pm S D ;{ }^{*} P<0.05,{ }^{* *} P<0.01$,

${ }^{* * *} P<0.001$. ns, not significant.

Additional file 3: Figure S3. Autophagy flux is blocked by ARCSP. Cells were treated with ARCSP $(75 \mu \mathrm{M})$ for $48 \mathrm{~h}$ and subjected to colocalization analysis of LC3B (488, green) and p62 (594, red). DAPI (blue) was used to stain the nuclei, and the cells were photographed under a fluorescence microscope. Scale bar $=25 \mu \mathrm{m}$.

Additional file 4: Figure S4. ARCSP treatment inhibits lysosomal activity. (A) Cells were treated with ARCSP $(75 \mu \mathrm{M})$ or CQ $(20 \mu \mathrm{M})$ for $48 \mathrm{~h}$, stained with Lyso Tracker-Red for 40 min, Hoechst 33342 (blue) was used to stain the nuclei, and photographed under a fluorescence microscope. Scale bar $=50 \mu \mathrm{m}$. (B) Cells were treated with ARCSP $(75 \mu \mathrm{M})$ for $48 \mathrm{~h}$, immunolabeling with CTSD (488 green) antibodies. DAPI (blue) was used to stain the nuclei, and the cells were photographed under a fluorescence microscope. Scale bar $=25 \mu \mathrm{m}$. (C) After HeLa and CaSki cells were treated with ARCSP $(0-75 \mu \mathrm{M})$ for $48 \mathrm{~h}$, we detected the expression of Galectin-3 by Western blotting.

Additional file 5: Figure S5. The combined therapy of ARCSP and cisplatin in HeLa and CaSki cells. (A) The HeLa and CaSki cells were treated with CDDP $(0-15 \mu \mathrm{M})$ for $48 \mathrm{~h}$, and cell viability was measured by CCK8 assay. (B) The HeLa and CaSki cells were co-treated with CDDP $(2.5 \mu \mathrm{M}, 5 \mu \mathrm{M}, 10 \mu \mathrm{M})$ or ARCSP $(0-100 \mu \mathrm{M})$ for $24 \mathrm{~h}$, and cell viability was measured by CCK8 assay. The data are expressed as the mean $\pm \mathrm{SD} ;{ }^{*} P<$ $0.05,{ }^{* *} P<0.01,{ }^{* * * *} P<0.001$. ns, not significant.

\section{Abbreviations}

ARCSP: Autophagy-related cancer suppressing peptide; FITC: Fluorescein isothiocyanate; ARCSP-FITC: Autophagy-related cancer suppressing peptide labeled with fluorescein isothiocyanate; CCK8: Cell counting kit-8; LDH: Cytotoxicity lactate dehydrogenase release; EDU: 5-ethynyl-20deoxyuridine; TUNEL: TdT-mediated dUTP Nick-End Labeling; AO: Acridine orange; QRT-PCR: Reverse transcription-polymerase chain reaction and realtime PCR; AMPK: Adenosine 5'-monophosphate activated protein kinase; mTOR: Mammalian target of rapamycin; PI: Propidium; DAPI: 4', 6'-diamidino2-phenylindole; LC3B: Microtubule associated protein 1 light chain 3 ; ATG7: Autophagy-related 7; ROS: Reactive oxygen species; ATP: Adenosine triphosphate; HPLC: High performance liquid chromatography; MS: Mass spectrometry; CQ: Chloroquine; NAC: N-acetyl-L-cysteine; 3-MA: 3Methyladenine; Rapa: Rapamycin; CC: Compound C; DCFH-DA: Oxidationsensitive probe dichlorodihydro-fluorescein diacetate; LAMP1: Recombinant lysosomal associated membrane protein 1; LAMP2: Recombinant lysosomal associated membrane protein 2; CTSD: Cathepsin D; PCNA: Proliferating cell nuclear antigen; APOC1: Apolipoprotein C

\section{Acknowledgements}

We would like to acknowledge our lab colleagues for their support in the development of this article.

\section{Authors' contributions}

YY and JXW carried out the experiments design, theoretical simulations and data analysis. YY and JXW carried out the experiments design, theoretical simulations and data analysis. YY, QW, and RRZ carried out test operation in animal experiment and cell experiment. DJS, YJW and LZ carried out measurements. YY wrote the manuscript. JXW, HYY and DZ revised the manuscript. JJ and JZ gave scientific advices. All the authors contributed through scientific discussion and reviewed the manuscript. The author(s) read and approved the final manuscript.

\section{Funding}

The study was conducted within the Department of Pediatric Surgery supported by the First Affiliated Hospital of Zhengzhou University. The study was financially supported by Henan Province Medical Science and Technology Key Project Co-construction Project (SB201901033) and National Natural Science Foundation of China (81902471)

\section{Availability of data and materials}

The data supporting the findings of this study are included in this paper and its additional files.

\section{Ethics approval and consent to participate}

The animal experiments conducted strictly in line with the Animal Study Guidelines of Chinese Academy of Medical Sciences.

\section{Consent for publication}

All authors have agreed to the publication of the article.

\section{Competing interests}

The authors have declared that no conflict of interest exists.

\section{Author details}

'Department of Pediatric Surgery, The First Affiliated Hospital of Zhengzhou University, Zhengzhou 450052, Henan, China. ${ }^{2}$ Departemnt of Oncology, The First Affiliated Hospital of Zhengzhou University, Zhengzhou 450052, Henan, China. 
Received: 17 February 2020 Accepted: 7 September 2020

Published online: 22 September 2020

\section{References}

1. Ginsburg O, Bray F, Coleman MP, Vanderpuye V, Eniu A, Kotha SR, et al. The global burden of women's cancers: a grand challenge in global health. Lancet (London, England). 2017;389(10071):847-60.

2. Basu P, Mehta A, Jain M, Gupta S, Nagarkar RV, John S, et al. A randomized phase 2 study of ADXS11-001 Listeria monocytogenes-Listeriolysin O immunotherapy with or without cisplatin in treatment of advanced cervical cancer. Int J Gynecol Cancer. 2018;28(4):764-72.

3. Hanahan D, Weinberg RA. The hallmarks of cancer. Cell. 2000;100(1):57-70.

4. Zhao W, Li J, Li P, Guo F, Gao P, Zhang J, et al. Wilms tumor-suppressing peptide inhibits proliferation and induces apoptosis of Wilms tumor cells in vitro and in vivo. J Cancer Res Clin Oncol. 2019;145(10):2457-68.

5. Yi J, Ren L, Wu J, Li W, Zheng X, Du G, et al. Apolipoprotein C1 (APOC1) as a novel diagnostic and prognostic biomarker for gastric cancer. Ann Transl Med. 2019;7(16):380.

6. Zhang J, Guo F, Wang L, Zhao W, Zhang D, Yang H, et al. Identification of apolipoprotein C-I as a potential Wilms' tumor marker after excluding inflammatory factors. Int J Mol Sci. 2014;15(9):16186-95.

7. Jin Y, Yang Y, Su Y, Ye X, Liu W, Yang Q, et al. Identification a novel clinical biomarker in early diagnosis of human non-small cell lung cancer. Glycoconj J. 2019;36(1):57-68.

8. Fan Y, Shi L, Liu Q, Dong R, Zhang Q, Yang S, et al. Discovery and identification of potential biomarkers of papillary thyroid carcinoma. Mo Cancer. 2009;8:79.

9. Sun Y, Zhang J, Guo F, Zhao W, Zhan Y, Liu C, et al. Identification of apolipoprotein $\mathrm{C}-\mathrm{I}$ peptides as a potential biomarker and its biological roles in breast cancer. Med Sci Monit. 2016;22:1152-60.

10. Zhang Q, Wang J, Dong R, Yang S, Zheng S. Identification of novel serum biomarkers in child nephroblastoma using proteomics technology. Mol Biol Rep. 2011;38(1):631-8.

11. Gregoriadis G, Jain S, Papaioannou I, Laing P. Improving the therapeutic efficacy of peptides and proteins: a role for polysialic acids. Int J Pharm. 2005;300(1-2):125-30.

12. Andrejeva G, Gowan S, Lin G, et al. De novo phosphatidylcholine synthesis is required for autophagosome membrane formation and maintenance during autophagy. Autophagy. 2020;16(6):1044-60.

13. Choi AM, Ryter SW, Levine B. Autophagy in human health and disease. N Engl J Med. 2013;368(19):1845-6

14. Rubinsztein DC, Codogno P, Levine B. Autophagy modulation as a potential therapeutic target for diverse diseases. Nat Rev Drug Discov. 2012;11(9):70930.

15. Button RW, Roberts SL, Willis TL, Hanemann CO, Luo S. Accumulation of autophagosomes confers cytotoxicity. J Biol Chem. 2017;292(33):13599-614.

16. Wang X, Du Z, Li L, Shi M, Yu Y. Beclin 1 and p62 expression in non-small cell lung cancer: relation with malignant behaviors and clinical outcome. Int J Clin Exp Pathol. 2015:8(9):10644-52.

17. Feng X, Zhou J, Li J, Hou X, Li L, Chen Y, et al. Tubeimoside I induces accumulation of impaired autophagolysosome against cervical cancer cells by both initiating autophagy and inhibiting lysosomal function. Cell Death Dis. 2018;9(11):1117.

18. Chen Y, McMillan-Ward E, Kong J, Israels SJ, Gibson SB. Oxidative stress induces autophagic cell death independent of apoptosis in transformed and cancer cells. Cell Death Differ. 2008:15(1):171-82.

19. Kawamoto M, Horibe T, Kohno M, Kawakami K. HER2-targeted hybrid peptide that blocks HER2 tyrosine kinase disintegrates cancer cell membrane and inhibits tumor growth in vivo. Mol Cancer Ther. 2013;12(4): 384-93.

20. Cao Q, You X, Xu L, Wang L, Chen Y. PAQR3 suppresses the growth of nonsmall cell lung cancer cells via modulation of EGFR-mediated autophagy. Autophagy. 2020;16(7):1236-47

21. Xu Y, Kim SO, Li Y, Han J. Autophagy contributes to caspase-independent macrophage cell death. J Biol Chem. 2006;281(28):19179-87.

22. Nakatogawa H. Mechanisms governing autophagosome biogenesis. Nat Rev Mol Cell Biol. 2020;21(8):439-58.

23. Li X, He S, Ma B. Autophagy and autophagy-related proteins in cancer. Mol Cancer. 2020;19(1):12.
24. Mulcahy Levy JM, Thorburn A. Autophagy in cancer: moving from understanding mechanism to improving therapy responses in patients. Cell Death Differ. 2020;27(3):843-57.

25. Wu WKK, Coffelt SB, Cho CH, Wang XJ, Lee CW, Chan FKL, et al. The autophagic paradox in cancer therapy. Oncogene. 2012;31(8):939-53.

26. Bhutia SK, Panda PK, Sinha N, Praharaj PP, Bhol CS, Panigrahi DP, et al. Plant lectins in cancer therapeutics: targeting apoptosis and autophagydependent cell death. Pharmacol Res. 2019;144:8-18.

27. Fulda S. Autophagy in cancer therapy. Front Oncol. 2017;7:128.

28. Das CK, Mandal M, Kögel D. Pro-survival autophagy and cancer cell resistance to therapy. Cancer Metastasis Rev. 2018;37(4):749-66.

29. Yan S, Yong-Hao H, Feng-Ying H, Wen-Li M, Quan L, Cai-Chun W, et al. 3'epi-12 $\beta$-hydroxyfroside, a new cardenolide, induces cytoprotective autophagy via blocking the Hsp90/Akt/mTOR axis in lung cancer cells. Theranostics. 2018;8(7):2044-60.

30. Bartlett BJ, Isakson P, Lewerenz J, Sanchez H, Kotzebue RW, Cumming RC, et al. p62, Ref(2)P and ubiquitinated proteins are conserved markers of neuronal aging, aggregate formation and progressive autophagic defects. Autophagy. 2011;7(6):572-83.

31. Tanida I. Autophagosome formation and molecular mechanism of autophagy. Antioxid Redox Signal. 2011;14(11):2201-14

32. Chen WR, Liu HB, Chen YD, Sha Y, Ma Q, Zhu PJ, et al. Melatonin attenuates myocardial ischemia/reperfusion injury by inhibiting autophagy via an AMPK/mTOR signaling pathway. Cell Physiol Biochem. 2018;47(5):2067-76.

33. Xie N, Yuan K, Zhou L, Wang K, Chen HN, Lei Y, et al. PRKAA/AMPK restricts HBV replication through promotion of autophagic degradation. Autophagy. 2016;12(9):1507-20.

34. Lin SC, Hardie DG. AMPK: sensing glucose as well as cellular energy status. Cell Metab. 2018;27(2):299-313.

35. Meley D, Bauvy C, Houben-Weerts JH, Dubbelhuis PF, Helmond MT, Codogno $\mathrm{P}$, et al. AMP-activated protein kinase and the regulation of autophagic proteolysis. J Biol Chem. 2006;281(46):34870-9.

36. Zhang CS, Li M, Lin SC. Methods to study lysosomal AMPK activation. Methods Enzymol. 2017;587:465-80.

37. Dikic I, Elazar Z. Mechanism and medical implications of mammalian autophagy. Nat Rev Mol Cell Biol. 2018;19(6):349-64.

38. Hamalisto S, Jaattela M. Lysosomes in cancer-living on the edge (of the cell). Curr Opin Cell Biol. 2016;39:69-76.

39. Luzio JP, Pryor PR, Bright NA. Lysosomes: fusion and function. Nat Rev Mol Cell Biol. 2007;8(8):622-32.

40. Zhang L, Wang K, Lei Y, Li Q, Nice EC, Huang C. Redox signaling: potential arbitrator of autophagy and apoptosis in therapeutic response. Free Radic Biol Med. 2015;89:452-65.

41. Rudzinska M, Parodi A, Soond SM, Vinarov AZ, Korolev DO, Morozov AO, et al. The role of cysteine cathepsins in cancer progression and drug resistance. Int J Mol Sci. 2019;20(14):3602.

42. Masud Alam M, Kariya R, Kawaguchi A, Matsuda K, Kudo E, Okada S. Inhibition of autophagy by chloroquine induces apoptosis in primary effusion lymphoma in vitro and in vivo through induction of endoplasmic reticulum stress. Apoptosis. 2016;21(10):1191-201.

43. Rosenfeld MR, Ye X, Supko JG, Desideri S, Grossman SA, Brem S, et al. A phase I/II trial of hydroxychloroquine in conjunction with radiation therapy and concurrent and adjuvant temozolomide in patients with newly diagnosed glioblastoma multiforme. Autophagy. 2014;10(8):1359-68.

44. Rangwala R, Chang YC, Hu J, Algazy KM, Evans TL, Fecher LA, et al. Combined MTOR and autophagy inhibition: phase I trial of hydroxychloroquine and temsirolimus in patients with advanced solid tumors and melanoma. Autophagy. 2014;10(8):1391-402.

45. Yue W, Hamai A, Tonelli G, Bauvy C, Nicolas V, Tharinger $H$, et al. Inhibition of the autophagic flux by salinomycin in breast cancer stem-like/progenitor cells interferes with their maintenance. Autophagy. 2013;9(5):714-29.

46. Zheng K, Li Y, Wang S, Wang X, Liao C, Hu X, et al. Inhibition of autophagosome-lysosome fusion by ginsenoside Ro via the ESR2-NCF1-ROS pathway sensitizes esophageal cancer cells to 5 -fluorouracil-induced cell death via the CHEK1-mediated DNA damage checkpoint. Autophagy. 2016; 12(9):1593-613.

\section{Publisher's Note}

Springer Nature remains neutral with regard to jurisdictional claims in published maps and institutional affiliations. 